OPEN ACCESS

Edited by:

Brandt D. Pence,

University of Memphis, United States

Reviewed by:

Nicolò Merendino,

University of Tuscia, Italy

Paul King,

Monash University, Australia

*Correspondence:

Emma J. Derbyshire

emma@nutritional-insight.co.uk

Specialty section:

This article was submitted to

Nutritional Immunology,

a section of the journal

Frontiers in Nutrition

Received: 12 January 2021

Accepted: 30 March 2021

Published: 29 April 2021

Citation:

Derbyshire EJ and Calder PC (2021)

Bronchiectasis-Could

Immunonutrition Have a Role to Play

in Future Management?

Front. Nutr. 8:652410.

doi: 10.3389/fnut.2021.652410

\section{Bronchiectasis-Could Immunonutrition Have a Role to Play in Future Management?}

\author{
Emma J. Derbyshire ${ }^{1 *}$ and Philip C. Calder ${ }^{2,3}$ \\ ${ }^{1}$ Nutritional Insight, London, United Kingdom, ${ }^{2}$ School of Human Development and Health, Faculty of Medicine, University of \\ Southampton, Southampton, United Kingdom, ${ }^{3}$ National Institute for Health Research (NIHR) Southampton Biomedical \\ Research Centre, University Hospital Southampton National Health Service (NHS) Foundation Trust, University of \\ Southampton, Southampton, United Kingdom
}

Bronchiectasis is a chronic condition in which areas of the bronchial tubes become permanently widened predisposing the lungs to infection. Bronchiectasis is an age-associated disease with the highest prevalence in people older than 75 years. While the prevalence of bronchiectasis is higher in males, disease is more severe in females who have a poorer prognosis. The overall prevalence of the disease is thought to be rising. Its aetiology is multi-faceted, but a compromised immune system is now thought to play a central role in the pathology of this disease. Research has begun to study the role of malnutrition and certain nutrients - vitamin D and zinc-along with the role of the lung microbiome in relation to the management of bronchiectasis. Given this, the present mini review sets out to provide an overview of the state-of-the-art within the field, identify research gaps and pave the way for future developments and research investment within this field.

Keywords: bronchiectasis, lung health, respiratory tract infections, immunonutrition, inflammation

\section{INTRODUCTION}

For a long time, bronchiectasis has been regarded as an "orphan disease," a disease so rare that it was not considered commercially viable to develop drugs to treat it (1). This led bronchiectasis to be regarded as unimportant and it was subsequently under-researched $(2,3)$. Now, into the twenty-first century, bronchiectasis is becoming an increasingly frequent prognosis and it has even been coined as an emerging global epidemic (4). In the United Kingdom (UK) there is evidence to suggest that both the prevalence and incidence of bronchiectasis are rising quickly (5). For example, for non-cystic fibrosis bronchiectasis, the UK incidence for women rose from 21.2 per 100,000 person-years in 2004 to 35.2 per 100,000 person-years in 2013 and for men from 18.2 per 100,000 person-years in 2004 to 26.9 per 100,000 person-years by 2013 (5). It was found that bronchiectasis is more common amongst those with higher socioeconomic status, although the reason for this is unclear (5). The British Lung Foundation's "Respiratory Health of the Nation" project estimated that $\sim 212,000$ people in the UK are living with bronchiectasis - levels higher than previously thought, with the severity of the condition more prevalent in females, in those aged over 70 years and in the least deprived sectors of the population, which is in contrast to other respiratory disorders (6). Sex differences, with females portending to worse clinical outcomes has, in part, been explained by differences in sex steroid hormones which may affect airway microbiology (7).

Bronchiectasis is characteristically caused by abnormal dilation of the bronchi and a damaged epithelium which, in turn, impairs mucus clearance and facilitates bacterial infection $(8,9)$. 
The condition is frequently accompanied by inflammation with symptoms manifesting as a chronic cough, sputum production and recurrent infections (10). For most people the causes behind bronchiectasis are "idiopathic" but some pathophysiological mechanisms include: dysregulation of the immune system, inflammatory conditions (e.g., bowel disease or arthritis), or structural lung problems (11). Amongst the array of causative factors behind bronchiectasis, the majority of these compromise the immune response in some form resulting in an impaired ability to fight infection (12).

Treatment strategies for bronchiectasis focus primarily on improving quality of life, preventing the frequency of flare ups and offsetting disease progression (8). Long term use of antibiotics-continuous or cyclical (during the winter months) - is typically recommended to stabilise the disease (13). Increasingly, there has been a growing body of evidence linking nutrition to immune function and protection against respiratory infections (14-16). Consequently, so-called immunonutrition could also have a role in bronchiectasis management - a field of science that appears to be underexplored. This minireview considers the science linking nutrition to bronchiectasis management and describes how this could be further advanced in the future. The focus of the present review is on non-cystic fibrosis bronchiectasis.

\section{IMMUNE DYSFUNCTION IN BRONCHIECTASIS}

King et al. stated that "the deficiency of the host immune response to bacterial infection is regarded as a primary requirement for the development of bronchiectasis" (12). While a spectrum of causative factors underpin bronchiectasis, the majority of these compromise immune function and the ability to fight infection (12). Both the adaptive and innate immune responses are activated in bronchiectasis (12), with neutrophils having a central role in bronchiectasis pathology. Inflammation is driven by neutrophils that migrate to the airway in response to elevated concentrations of chemokines and pro-inflammatory cytokines, which are elevated in the airways of these patients (17). Neutrophils would typically phagocytose and kill pathogenic bacteria, but in patients with bronchiectasis these appear to have been disabled, possibly by the cleavage of phagocytic receptors by neutrophil elastase (17). An excessive release of neutrophil elastase is known to have damaging effects on the lungs, including impaired ciliary beat frequency, airway epithelia destruction, mucus gland stimulation and increased sputum production (18). Other mechanisms related to immune dysfunction are also evident in patients with bronchiectasis. For example, proteases produced in the lung as a result of the inflammatory response result in pathological dilation that is characteristic of bronchiectasis (12).

\section{SPECIFIC IMMUNONUTRIENTS AND BRONCHIECTASIS}

Optimal functioning of the immune system is central to human health, and nutrition is one of the main exogenous factors involved in the modulation of immune function (19). The British Thoracic Society presently provides guidelines for adults with bronchiectasis, which include advice on airway clearance techniques, use of mucoactive treatments, anti-inflammatory therapies, and antibiotic use (20). Nutritional advice is not presently included, perhaps because of an historic lack of relevant evidence. However, recent research has begun to investigate the role of nutrition in bronchiectasis and respiratory infection management.

It is now becoming relatively well-established that vitamin D supplementation could help to attenuate respiratory tract infections (RTIs) $(21,22)$. Vitamin D receptors are present in almost all cells of the immune system, vitamin D thus being important to the regulation of both innate and adaptive immunity (23). For example, vitamin D receptors are found on monocytes which differentiate into macrophages under the effects of $1,25(\mathrm{OH})_{2} \mathrm{D}$ (24). Macrophages and dendritic cells also express their own $1 \alpha$-hydroxylase isoenzyme which synthesises $1,25(\mathrm{OH})_{2} \mathrm{D}$ intracellularly (25). Vitamin $\mathrm{D}$ receptors are further present on T-cells, B-cells and monocytes (26). As well as possessing immunomodulatory functions, vitamin $\mathrm{D}$ is also known to increase the antiviral responses of respiratory epithelial cells during infections (27). Vitamin D has been found to enhance neutrophil killing in patients with bacterial respiratory tract infections (RTIs) and to lower pro-inflammatory cytokine production induced by infected neutrophils (28). Amongst patients with cystic fibrosis, vitamin D status correlated with immunoglobulin concentrations and reduced CD279 programmed death 1 (PD-1) expression on $\mathrm{CD}^{+} \mathrm{T}$ cells and the frequency of $\mathrm{CD} 8^{+} \mathrm{T}$ cells co-expressing CD38 and human leucocyte antigen D-related (29). Vitamin D also induces antimicrobial peptide gene expression including that of cathelicidins and defensins which possess the ability to disrupt the integrity of the pathogens, resulting in their apoptosis (30). These mechanisms could, in part, explain some of the "antibiotic" actions of vitamin D (30). Together, these observations suggest that vitamin $\mathrm{D}$ could have a potential extended role to play in bronchiectasis management.

Clearly, the pathogenesis of bronchiectasis is multi-faceted with autoimmune disease, conditions of immune dysregulation, genetics, geography, and ethnicity having underpinning roles (9). As shown in Table 1 several nutritional risk factors could also contribute to bronchiectasis pathology. These includes malnutrition, pro-inflammatory diets, suboptimal hydration status and vitamin D and zinc shortfalls. Malnutrition and an imbalance between energy supply and requirements can result in a negative balance between protein synthesis and breakdown, potentially affecting the prognosis of respiratory diseases (31). A growing body of evidence now links pro-inflammatory diets to disease-related fatigue whilst balanced diets comprised of wholegrains, polyphenols-rich vegetables and foods providing omega3 fatty acids may attenuate fatigue related to chronic disease (33). Adequate hydration is important for mucociliary clearance, helping to reduce concentrations and cohesion (38).

Several trials suggesting a link between low vitamin D status and bronchiectasis have been published (Table 2). Scottish research measuring serum vitamin $\mathrm{D}$ levels in patients with bronchiectasis $(n=402)$ found that $50 \%$ were deficient, $43 \%$ 
TABLE 1 | Bronchiectasis: potential modifiable nutritional risk factors.

\begin{tabular}{|c|c|c|}
\hline Dietary component & Explanation and potential pathway(s) & Reference(s) \\
\hline Malnutrition & $\begin{array}{l}\text { Malnutrition (lack of adequate nutrition) can cause diverse alterations in the innate and adaptive immune } \\
\text { responses. These include the involution of the thymus, reducing } T \text { cell numbers and responses and exacerbating } \\
\text { the susceptibility to infections. }\end{array}$ & $(31,32)$ \\
\hline Pro-inflammatory diets & $\begin{array}{l}\text { Several foods and dietary patterns have been identified as pro-inflammatory, inducing secretion of inflammatory } \\
\text { mediators, and free radicals. Those most studied include hydrogenated fats, processed foods, and refined sugars. } \\
\text { In contrast, balanced diets comprised of whole-grains, polyphenol-rich vegetables and foods providing omega-3 } \\
\text { fatty acids may attenuate inflammation (so reducing fatigue related to chronic disease). }\end{array}$ & $(32-34)$ \\
\hline Zinc & $\begin{array}{l}\text { Zinc is regarded as the gatekeeper of immune function and could be of benefit in instances when the immune } \\
\text { system is functioning poorly. } \\
\text { Zinc is thought to activate key signalling molecules and induce epigenetic modifications that underpin its roles as a } \\
\text { gatekeeper of immune function. }\end{array}$ & (37) \\
\hline
\end{tabular}

TABLE 2 | Summary of studies of nutrients and the lung microbiota in bronchiectasis.

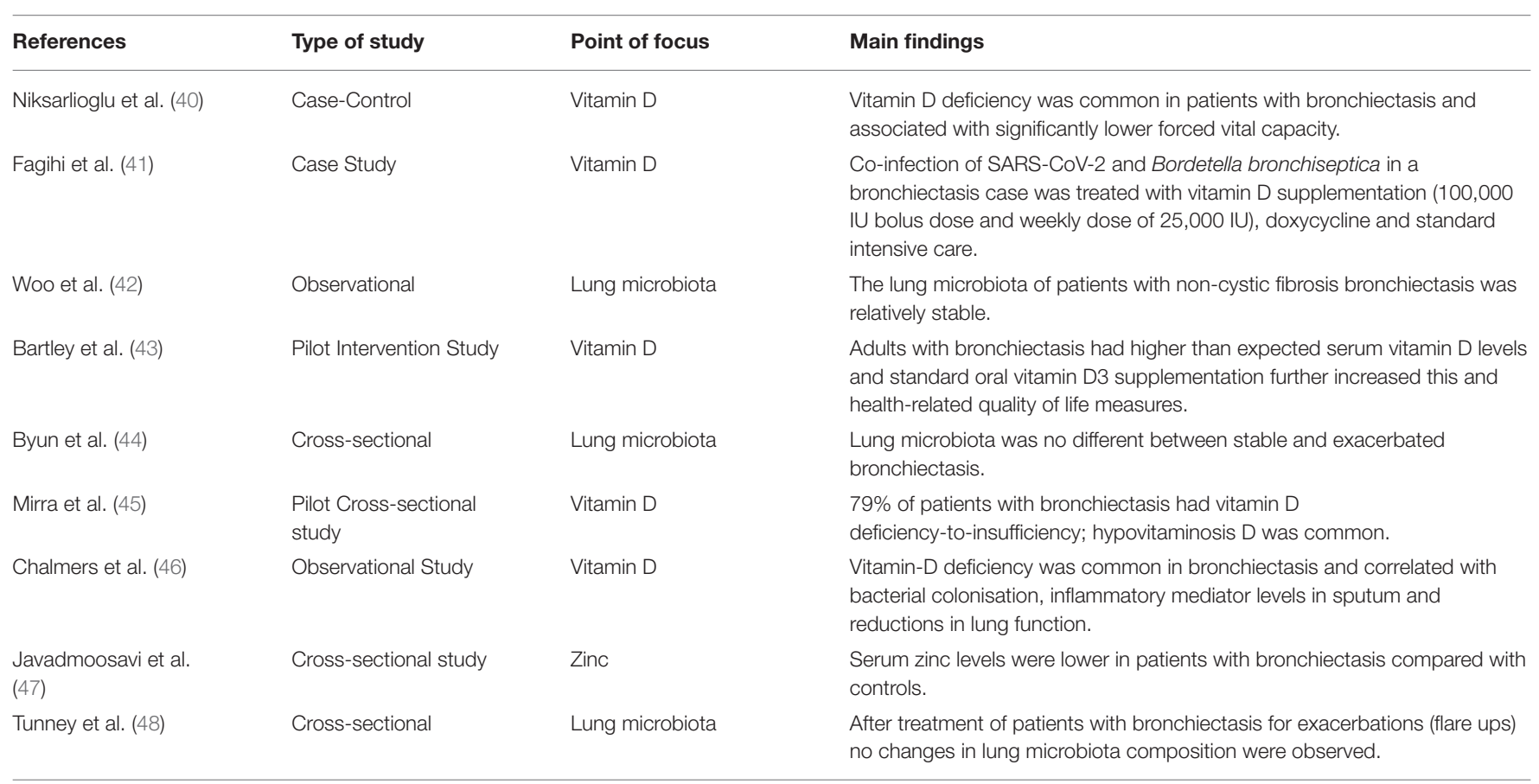

insufficient and only 7\% had sufficient status (46). Additionally, $24 \%$ of the vitamin D deficient patients were colonised with Pseudomonas aeruginosa, had elevated sputum inflammatory marker levels and were more likely to have a decline in lung function at follow-up (46). A case-control study involving 130 Turkish cases with bronchiectasis observed that vitamin D deficiency was common and significantly associated with reduced forced vital lung capacity (40). Similarly, a pilot study conducted in New Zealand found that adults with bronchiectasis had a tendency towards sub-optimal serum vitamin D levels and weekly supplementation with $0.6 \mathrm{mg}$ vitamin D3 (after a loading dose of $2.5 \mathrm{mg}$ ) significantly increased serum vitamin D levels (43). Amongst patients with primary ciliary dyskinesia (64\% with bronchiectasis) hypovitaminosis D was evident in 79\% (45). Interestingly, in a recent case study of a young male with severe acute respiratory syndrome coronavirus-2 (SARS-CoV-2), 
the virus which causes COVID-19, bronchiectasis and Bordetella bronchiseptica colonisation were treated successfully with a vitamin D3 intervention, doxycycline and intensive care (41).

Zinc is another nutrient known to support the function of many immune cell types and to benefit respiratory infections (49). Zinc is the chief regulator of signal transduction and cellular function, with zinc deficiency altering zinc homeostasis and molecular mechanisms including the actions of kinases, caspases, phosphatases, and phosphodiesterases which can exacerbate infection susceptibility (50). In vivo research also shows that zinc deficiency modulates the function and number of monocytes, neutrophils, natural killer, B-, and T-cells, with T-cell balance and function being particularly receptive to changes in zinc status (51).

To date only one study has investigated a potential role of zinc in bronchiectasis; the study found that serum zinc levels were significantly lower in patients with bronchiectasis compared with controls (47). The authors concluded that zinc could have extended benefits helping to modulate the immune system in these patients (47). Therefore, studies are now warranted that focus on zinc status/supplementation programmes in relation to specific markers of immune function (e.g., T-cell function), lung function and infection in bronchiectasis cases.

The microbiota also interacts with the local immune system. Most research has focussed on the role of the gut microbiota, which may affect both gastrointestinal and respiratory illness, but the lung microbiota is also now recognised to be important $(52,53)$. The lung airway microbiota is low in biomass compared to the gut, yet could be a powerful regulator of the immune system (54). As with the gut there is likely to be a bidirectional relationship between the lung microbiota and host epithelial and immune cells. For example, lung epithelial cells are being recognised as active effectors of microbial defence, contributing to both adaptive and innate immune function in the lower respiratory tract (55).

A small number of studies have begun to investigate the profile of the lung microbiota in patients with bronchiectasis $(42,44,48)$. In general, the lung microbiota has been found to be relatively stable in these patients, with few differences between remission and flare-up of disease although comparisons with healthy adults are warranted $(42,44,48)$.

\section{DISCUSSION}

Immunonutrition could be a means of reducing bronchiectasisrelated infection and disease progression, which over time can result in impaired lung function. A number of nutrients support the immune system including vitamins B6, B9 (folate), B12, $\mathrm{C}, \mathrm{D}$ and $\mathrm{E}$, zinc, copper, iron and selenium and essential amino acids and fatty acids $(15,16,56)$. There is now metaanalytical evidence available, which demonstrates that vitamin D supplementation reduces the risk of respiratory tract infections $(21,22,57)$. In the UK, Biobank data shows that Asian and black residents have higher rates of vitamin D deficiency (54 and 35\%) than Caucasians (12\%) and socioeconomic deprivation, smoking and northerly latitudes increased the odds of vitamin D deficiency (58).

Zinc may also reduce risk of such infections and a recent rapid review of 118 publications concluded that zinc could reduce the risk, duration, and severity of SARS-CoV2 and other respiratory virus infections through several mechanisms which include its potential to reduce inflammation, interfere with SARS-CoV-2 replication, improve mucocilliary clearance, promote antiviral immunity and reduce the risk of co-infection with pneumonia (59). Malabsorption syndromes and the consumption of high phytate-containing cereals in the developing world have been associated with high rates of zinc deficiencies (60). In addition to traditional essential nutrients, many plant-derived dietary components, including flavonoids, may also support the immune response and regulate inflammation. A meta-analysis of 14 studies reports that flavonoid supplementation reduced upper respiratory tract infection incidence by $33 \%$ compared with control, although differences between immune markers between groups were found to be modest (61).

As indicated earlier, there are observations of low vitamin D and zinc status being linked to bronchiectasis, but randomised controlled trials looking at effects on immune markers, lung function and infection with these two nutrients, and with other potential candidates, are lacking. This is an important research gap. Currently neither the British Thoracic Society nor the European Respiratory Society bronchiectasis guidelines include any nutritional advice $(20,62)$. Given the potential for nutrients to play a useful role in disease management, more research in this area is warranted. Current advice for the UK general population is to take a 10 microgram daily supplement of vitamin D to keep bones, teeth, and muscles healthy (63). However, intakes of 2,000 IU/day (50 micrograms/day) seem to be needed to reduce the risk of respiratory tract infections (16). Vitamin D deficiency may play a role in the pathogenesis of bronchiectasis and vitamin D supplementation could be a cost-effective therapeutic approach to help manage and attenuate the severity and progression of this disease (64), if it was supported by quality research evidence.

Regarding the roles of other nutrients and the lung microbiota and its modulation, there is presently not enough evidence to make any clear conclusions. Research on candidate nutrients other than vitamin $\mathrm{D}$ is warranted; high quality trials focusing on vitamin $\mathrm{D}$, zinc, other nutrients, and flavonoids and immuneand bronchiectasis-markers would be worthy of future study $(15,16,65)$. Research focusing on the gut and lung microbiota in patients with bronchiectasis over extended time periods and using larger sample sizes to capture disease heterogeneity during stability and at exacerbation is warranted (66).

\section{CONCLUDING REMARKS}

Bronchiectasis is a progressive immune-infective-inflammatory airway condition that results in a vicious cycle of repeated exacerbations and irreversible damage. It is becoming more common. Whilst conventional medical approaches are clearly 
crucial to its management, immunonutrition could also have a viable role to play, with evidence for vitamin D currently being the most promising. Given growing interest in lung health, in part sparked by the SARS-CoV-2 pandemic, greater focus and investment in research is needed in this disease.

\section{REFERENCES}

1. Mobaireek K. Noncystic fibrosis bronchiectasis: is it an orphan disease? Ann Thorac Med. (2007) 2:2. doi: 10.4103/1817-1737.30353

2. O'Donnell AE. Bronchiectasis update. Curr Opin Infect Dis. (2018) 31:194-8. doi: 10.1097/QCO.0000000000000445

3. Goeminne P, De Soyza A. Bronchiectasis: how to be an orphan with many parents? Eur Respir J. (2016) 47:10-3. doi: 10.1183/13993003.01567-2015

4. Chotirmall SH, Chalmers JD. Bronchiectasis: an emerging global epidemic. BMC Pulm Med. (2018) 18:76. doi: 10.1186/s12890-018-0629-1

5. Quint JK, Millett ER, Joshi M, Navaratnam V, Thomas SL, Hurst JR, et al. Changes in the incidence, prevalence and mortality of bronchiectasis in the UK from 2004 to 2013: a population-based cohort study. Eur Respir J. (2016) 47:186-93. doi: 10.1183/13993003.01033-2015

6. Snell N, Gibson J, Jarrold I, Quint JK. Epidemiology of bronchiectasis in the UK: findings from the British lung foundation's 'Respiratory health of the nation' project. Respir Med. (2019) 158:21-3. doi: 10.1016/j.rmed.2019.09.012

7. Vidaillac C, Yong VFL, Jaggi TK, Soh MM, Chotirmall SH. Gender differences in bronchiectasis: a real issue? Breathe. (2018) 14:108-21. doi: $10.1183 / 20734735.000218$

8. Chalmers JD, Chang AB, Chotirmall SH, Dhar R, McShane PJ. Bronchiectasis. Nat Rev Dis Primers. (2018) 4:45. doi: 10.1038/s41572-018-0042-3

9. Boyton RJ, Altmann DM. Bronchiectasis: current concepts in pathogenesis, immunology, and microbiology. Annu Rev Pathol. (2016) 11:523-54. doi: 10.1146/annurev-pathol-012615-044344

10. Magis-Escurra C, Reijers MH. Bronchiectasis. BMJ Clin Evid. (2015) 2015:1507.

11. BLF. British Lung Foundation. What Is Bronchiectasis and How Is It Caused? (2020) Available online at: https://www.blf.org.uk/support-for-you/ bronchiectasis/what-is-it (accessed April 15, 2021).

12. King PT. The role of the immune response in the pathogenesis of bronchiectasis. Biomed Res Int. (2018) 2018:6802637. doi: $10.1155 / 2018 / 6802637$

13. Melani AS, Lanzarone N, Rottoli P. The pharmacological treatment of bronchiectasis. Expert Rev Clin Pharmacol. (2018) 11:245-58. doi: 10.1080/17512433.2018.1421064

14. Childs CE, Calder PC, Miles EA. Diet and immune function. Nutrients. (2019) 11:1933. doi: 10.3390/nu11081933

15. Calder P. Feeding the immune system. Proc Nutr Soc. (2013) 73:299-309. doi: 10.1017/S0029665113001286

16. Calder PC, Carr AC, Gombart AF, Eggersdorfer M. Optimal nutritional status for a well-functioning immune system is an important factor to protect against viral infections. Nutrients. (2020) 12:1181. doi: 10.3390/nu12041181

17. Chalmers JD, Hill AT. Mechanisms of immune dysfunction and bacterial persistence in non-cystic fibrosis bronchiectasis. Mol Immunol. (2013) 55:2734. doi: 10.1016/j.molimm.2012.09.011

18. Gramegna A, Aliberti S, Sibila O, Di Francesco C, Sotgiu G, Perea L, et al. Sputum neutrophil elastase in bronchiectasis: a Southern European cohort study. Eur Respir J. (2020) 56. doi: 10.1183/13993003.01702-2020

19. Albers R, Bourdet-Sicard R, Braun D, Calder PC, Herz U, Lambert C, et al. Monitoring immune modulation by nutrition in the general population: identifying and substantiating effects on human health. Br J Nutr. (2013) 110 (Suppl. 2):S1-30. doi: 10.1017/S0007114513001505

20. Hill AT, Sullivan AL, Chalmers JD, De Soyza A, Elborn SJ, Floto AR, et al. British thoracic society guideline for bronchiectasis in adults. Thorax. (2019) 74:1-69. doi: 10.1136/thoraxjnl-2018-212463

21. Martineau AR, Thummel KE, Wang Z, Jolliffe DA, Boucher BJ, Griffin SJ, et al. differential effects of oral boluses of vitamin D2 vs vitamin D3 on vitamin

\section{AUTHOR CONTRIBUTIONS}

ED and PC compiled, researched, wrote, and edited the review. All authors contributed to the article and approved the submitted version.

D metabolism: a randomized controlled trial. J Clin Endocrinol Metab. (2019) 104:5831-39. doi: 10.1210/jc.2019-00207

22. Jolliffe DA, Ganmaa D, Wejse C, Raqib R, Haq MA, Salahuddin $\mathrm{N}$, et al. Adjunctive vitamin $\mathrm{D}$ in tuberculosis treatment: metaanalysis of individual participant data. Eur Respir J. (2019) 53:1802003. doi: 10.1183/13993003.02003-2018

23. Martens PJ, Gysemans C, Verstuyf A, Mathieu AC. Vitamin D's effect on immune function. Nutrients. (2020) 12:1248. doi: 10.3390/nu12051248

24. Provvedini DM, Deftos LJ, Manolagas SC. 1,25-Dihydroxyvitamin D3 promotes in vitro morphologic and enzymatic changes in normal human monocytes consistent with their differentiation into macrophages. Bone. (1986) 7:23-8. doi: 10.1016/8756-3282(86)90148-1

25. Zittermann A. Vitamin D in preventive medicine: are we ignoring the evidence? Br J Nutr. (2003) 89:552-72. doi: 10.1079/BJN2003837

26. Prietl B, Treiber G, Pieber TR, Amrein K. Vitamin D and immune function. Nutrients. (2013) 5:2502-21. doi: 10.3390/nu5072502

27. Balla M, Merugu GP, Konala VM, Sangani V, Kondakindi H, Pokal M, et al. Back to basics: review on vitamin $\mathrm{D}$ and respiratory viral infections including COVID-19. J Community Hosp Intern Med Perspect. (2020) 10:52936. doi: 10.1080/20009666.2020.1811074

28. Subramanian K, Bergman P, Henriques-Normark B. Vitamin D promotes pneumococcal killing and modulates inflammatory responses in primary human neutrophils. J Innate Immun. (2017) 9:375-86. doi: $10.1159 / 000455969$

29. Pincikova T, Paquin-Proulx D, Sandberg JK, Flodstrom-Tullberg M, Hjelte L. Vitamin D treatment modulates immune activation in cystic fibrosis. Clin Exp Immunol. (2017) 189:359-71. doi: 10.1111/cei.12984

30. Gombart AF. The vitamin D-antimicrobial peptide pathway and its role in protection against infection. Future Microbiol. (2009) 4:1151-65. doi: $10.2217 / \mathrm{fmb} .09 .87$

31. Gea J, Sancho-Munoz A, Chalela R. Nutritional status and muscle dysfunction in chronic respiratory diseases: stable phase versus acute exacerbations. $J$ Thorac Dis. (2018) 10:S1332-54. doi: 10.21037/jtd.2018.02.66

32. Morais AHA, Aquino JS, da Silva-Maia JK, Vale SHL, Maciel BLL, Passos TS. Nutritional status, diet and viral respiratory infections: perspectives for severe acute respiratory syndrome coronavirus 2. Br J Nutr. (2020) 125:851-62. doi: 10.1017/S0007114520003311

33. Hass U, Herpich C, Norman K. Anti-inflammatory diets and fatigue. Nutrients. (2019) 11:2315. doi: 10.3390/nu11102315

34. Christ A, Lauterbach M, Latz E. Western diet and the immune system: an inflammatory connection. Immunity. (2019) 51:794-811. doi: 10.1016/j.immuni.2019.09.020

35. Zittermann A, Pilz S, Hoffmann H, Marz W. Vitamin D and airway infections: a European perspective. Eur J Med Res. (2016) 21:14. doi: 10.1186/s40001-016-0208-y

36. Roy S, Shrinivas K, Bagchi B. A stochastic chemical dynamic approach to correlate autoimmunity and optimal vitamin-D range. PLoS ONE. (2014) 9:e100635. doi: 10.1371/journal.pone.0100635

37. Wessels I, Maywald M, Rink L. Zinc as a gatekeeper of immune function. Nutrients. (2017) 9:1286. doi: 10.3390/nu9121286

38. Button B, Goodell HP, Atieh E, Chen YC, Williams R, Shenoy S, et al. Roles of mucus adhesion and cohesion in cough clearance. Proc Natl Acad Sci USA. (2018) 115:12501-6. doi: 10.1073/pnas.1811787115

39. EFSA. Scientific opinion on dietary reference values for water. EFSA panel on dietetic products, nutrition, and allergies (NDA). EFSA J. (2010) 8:1459. doi: 10.2903/j.efsa.2010.1459

40. Niksarlioglu EY, Kilic L, Bilici D, Yigitbas B, Uysal MA, Camsari G. Vitamin $\mathrm{D}$ deficiency and radiological findings in adult non-cystic fibrosis 
bronchiectasis. Turk Thorac J. (2020) 21:87-92. doi: 10.5152/TurkThoracJ. 2019.18139

41. Faqihi F, Alharthy A, Pirompanich P, Noor A, Shahzad A, Nasim N, et al. Coinfection of SARS-CoV-2 and Bordetella bronchiseptica in a young man with idiopathic non-cystic bronchiectasis and vitamin D3 deficiency. Respir Med Case Rep. (2020) 31:101203. doi: 10.1016/j.rmcr.2020.101203

42. Woo TE, Lim R, Heirali AA, Acosta N, Rabin HR, Mody CH, et al. A longitudinal characterization of the non-cystic fibrosis bronchiectasis airway microbiome. Sci Rep. (2019) 9:6871. doi: 10.1038/s41598-019-42862-y

43. Bartley J, Garrett J, Camargo CA Jr, Scragg R, Vandal A, Sisk R, et al. Vitamin D3 supplementation in adults with bronchiectasis: a pilot study. Chron Respir Dis. (2018) 15:384-92. doi: 10.1177/1479972318761646

44. Byun MK, Chang J, Kim HJ, Jeong SH. Differences of lung microbiome in patients with clinically stable and exacerbated bronchiectasis. PLOS ONE. (2017) 12:e0183553. doi: 10.1371/journal.pone.0183553

45. Mirra V, Caffarelli C, Maglione M, Valentino R, Perruolo G, Mazzarella C, et al. Hypovitaminosis D: a novel finding in primary ciliary dyskinesia. Ital J Pediatr. (2015) 41:14. doi: 10.1186/s13052-015-0119-5

46. Chalmers J, McHugh B, Docherty C, Govan J, Hill A. Vitamin-D deficiency is associated with chronic bacterial colonisation and disease severity in bronchiectasis. Thorax. (2013) 68:39-47. doi: 10.1136/thoraxjnl-2012-202125

47. Javadmoosavi SA, Shahabi Shahmiri S, Mostafapour E, Purfakharan M, Zamanzadeh M, Fereshtehnejad SM, et al. Comparison of the serum concentration of zinc in patients with bronchiectasis and control group. Iran Red Crescent Med J. (2013) 15:587-9. doi: 10.5812/ircmj.7735

48. Tunney MM, Einarsson GG, Wei L, Drain M, Klem ER, Cardwell C, et al. Lung microbiota and bacterial abundance in patients with bronchiectasis when clinically stable and during exacerbation. Am J Respir Crit Care Med. (2013) 187:1118-26. doi: 10.1164/rccm.201210-1937OC

49. Maares $M$, Haase $H$. Zinc and immunity: an essential interrelation. Arch Biochem Biophys. (2016) 611:58-65. doi: 10.1016/j.abb.2016. 03.022

50. Maywald M, Wessels I, Rink L. Zinc signals and immunity. Int J Mol Sci. (2017) 18:2222. doi: 10.3390/ijms18102222

51. Haase H, Rink L. Zinc signals and immune function. Biofactors. (2014) 40:27-40. doi: 10.1002/biof.1114

52. Wang J, Li F, Tian Z. Role of microbiota on lung homeostasis and diseases. Sci China Life Sci. (2017) 60:1407-15. doi: 10.1007/s11427-017-9151-1

53. Dumas A, Bernard L, Poquet Y, Lugo-Villarino G, Neyrolles O. The role of the lung microbiota and the gut-lung axis in respiratory infectious diseases. Cell Microbiol. (2018) 20:e12966. doi: 10.1111/cmi.12966

54. Lloyd CM, Marsland BJ. Lung homeostasis: influence of age, microbes, and the immune system. Immunity. (2017) 46:549-61. doi: 10.1016/j.immuni.2017.04.005

55. Invernizzi R, Lloyd CM, Molyneaux PL. Respiratory microbiome and epithelial interactions shape immunity in the lungs. Immunology. (2020) 160:171-82. doi: 10.1111/imm.13195
56. Gombart AF, Pierre A, Maggini S. A review of micronutrients and the immune system-working in harmony to reduce the risk of infection. Nutrients. (2020) 12:236. doi: $10.3390 /$ nu12010236

57. Charan J, Goyal JP, Saxena D, Yadav P. Vitamin D for prevention of respiratory tract infections: a systematic review and meta-analysis. $J$ Pharmacol Pharmacother. (2012) 3:300-3. doi: 10.4103/0976-500X.103685

58. Lin LY, Smeeth L, Langan S, Warren-Gash C. Distribution of vitamin D status in the UK: a cross-sectional analysis of UK Biobank. BMJ Open. (2021) 11:e038503. doi: 10.1136/bmjopen-2020-038503

59. Arentz S, Hunter J, Yang G, Goldenberg J, Beardsley J, Myers SP, et al. Zinc for the prevention and treatment of SARS-CoV-2 and other acute viral respiratory infections: a rapid review. Adv Integr Med. (2020) 7:252-60. doi: 10.1016/j.aimed.2020.07.009

60. Prasad AS. Discovery of human zinc deficiency: its impact on human health and disease. Adv Nutr. (2013) 4:176-90. doi: 10.3945/an.112.003210

61. Somerville VS, Braakhuis AJ, Hopkins WG. Effect of flavonoids on upper respiratory tract infections and immune function: a systematic review and meta-analysis. Adv Nutr. (2016) 7:488-97. doi: 10.3945/an.115.010538

62. Polverino E, Goeminne PC, McDonnell MJ, Aliberti S, Marshall SE, Loebinger MR, et al. European Respiratory Society guidelines for the management of adult bronchiectasis. Eur Respir J. (2017) 50:1700629. doi: 10.1183/13993003.00629-2017

63. PHE. PHE Publishes New Advice on Vitamin D (2016/2020). Available online at: https://www.gov.uk/government/news/phe-publishes-new-adviceon-vitamin-d (accessed April 15, 2021).

64. Moustaki M, Loukou I, Priftis KN, Douros K. Role of vitamin D in cystic fibrosis and non-cystic fibrosis bronchiectasis. World J Clin Pediatr. (2017) 6:132-42. doi: 10.5409/wjcp.v6.i3.132

65. Maggini S, Pierre A, Calder PC. Immune function and micronutrient requirements change over the life course. Nutrients. (2018) 10:1531. doi: 10.3390/nu10101531

66. Richardson H, Dicker AJ, Barclay H, Chalmers JD. The microbiome in bronchiectasis. Eur Respir Rev. (2019) 28:190048. doi: 10.1183/16000617.0048-2019

\section{Conflict of Interest: ED is the founder of Nutritional Insight.}

The remaining author declares that the research was conducted in the absence of any commercial or financial relationships that could be construed as a potential conflict of interest.

Copyright $\odot 2021$ Derbyshire and Calder. This is an open-access article distributed under the terms of the Creative Commons Attribution License (CC BY). The use, distribution or reproduction in other forums is permitted, provided the original author(s) and the copyright owner(s) are credited and that the original publication in this journal is cited, in accordance with accepted academic practice. No use, distribution or reproduction is permitted which does not comply with these terms. 